\title{
Atmospheric ice accretion on air intake louvers of buildings in cold regions
}

\author{
Muhammad S. Virk* \\ High North Technology Centre, Department of Technology \\ Narvik University College, Norway
}

\begin{abstract}
In cold regions, air intake louvers are installed on buildings so as to deflect foreign matter like ice and snow particles and prevent them from entering the buildings, while allowing air to pass. In this research work a CFD based parametric numerical study has been carried out to simulate the rate and shape of atmospheric ice accretion on air intake louvers and to analyse the effects of various geometric parameters of louvers such as: placement angle, shape and size on the resultant ice accretion. It was concluded that ice mainly accretes at the front and top sides of the louver surface. It was also found that the rate of ice accretion increase in louver angle and the spacing between the louver slats.
\end{abstract}

Keywords: atmospheric ice, air intake louver, building, CFD, angle, shape.

\section{INTRODUCTION}

Louvers are a system of horizontal or vertical slats that are angled in such a manner so as to admit light and air, but to simultaneously keep out rain, direct sunshine and noise. A louvered opening has a series of slats integrated into a frame (Figure-1). Louvers are generally installed at air inlets of vehicle exteriors, screening fences of buildings, heat exchangers etc. [1]. In addition to controlling airflow, louvers are a source of solar heat gain; providing daylight as well as visual and auditory connection for the occupants with the external environment [2]. Buildings ventilation through air louvers is generally induced by the pressure difference driven by air motion between indoor and outdoor air. Size, location and orientatin of the louvers' openings have an impact on their performance [3]. Research on the use of louvers for natural ventealtion is limited [4]. Yakub [5] studied pressure drop across various louver inclinations. The effects of various parameters of louver such as: slat depth, opening and room depth were studied by Sharples and Maghrabi [6]. Tablada [7] found that variable inclinations of the louver slats are benificial for indoor flow distribution. Hughes and Ghani analysed the effect of changing angles of windvent louvers on the internal pressure loss and velocity of the stack ventilation system [8].

In cold regions, louvers are installed on buildings to deflect foreign matters like ice and snow particles, while allowing air to pass through. These ice and snow particles also accrete on the louver surface and cause a hinderence for the air flow and lead to a possible

${ }^{*}$ Corresponding author. E-mail: msv@hin.no 

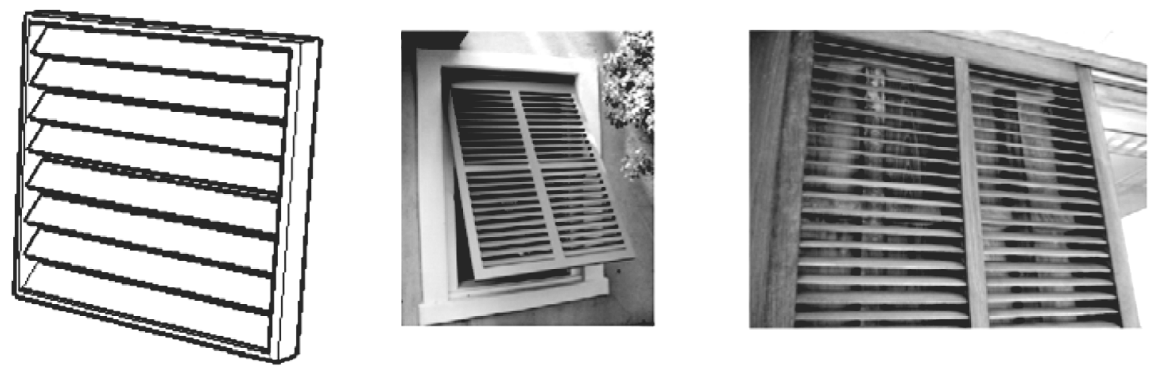

Figure 1 Examples of air intake louvers structure in buildings; source [2].

air pressure drop. Atmospheric ice accretion on louvers occurs when freezing rain drops, snow particles or super cooled water droplets come into contact with their exposed surface [9]. Super cooled water droplets impact with the structure of the louvers and accrete on them, which consequently acts as an obstruction for the passage of air. This causes an increase in pressure gradient between the two sides of the louvers and affects room venetlation. Not much work has been reported on the rate and shape of ice accretion on air intake louvers installed on buildings in cold regions. The present work attempts to numerically simulate the effects of ice accretion on louvers' openings and to study the effect of various geometric parameters of louvers such as: slat placement angle, shape and size on the resultant rate and shape of ice accretion on louvers.

\section{NUMERICAL SETUP}

The numerical study of atmospheric ice accretion on structures includes the computation of mass flux of icing particles as well as the determination of icing conditions [10]. These can be numerically simulated by means of integrated thermo-fluid dynamic models, which involve fluid flow simulation, droplet behavior, surface thermodynamics and phase changes. The numerical study was carried out using finite element analysis based on nonlinear partial differential equations for the conservation of mass, momentum and energy, equations (1), (2) and (3) respectively:

$$
\begin{aligned}
& \frac{\partial \rho_{a}}{\partial t}+\vec{\nabla} \cdot\left(\rho_{a} V_{a}\right)=0 \\
& \frac{\partial \rho_{a} \overrightarrow{V_{a}}}{\partial t}+\vec{\nabla} \cdot\left(\rho_{a} \overrightarrow{V_{a} V_{a}}\right)=\vec{\nabla} \cdot \sigma^{i j}+\rho_{a} \vec{g} \\
& \frac{\partial \rho_{a} E_{a}}{\partial t}+\vec{\nabla} \cdot\left(\rho_{a} \overrightarrow{V_{a}} H_{a}\right)=\vec{\nabla} \cdot\left(k_{a}\left(\vec{\nabla} T_{a}\right)+v_{i} \tau^{i j}\right)+\rho_{a} \vec{g} \cdot \overrightarrow{V_{a}}
\end{aligned}
$$

Where $\sigma^{i j}$ is the stress tensor, $k$ is the thermal conductivity, $E$ is the internal energy and $H$ is the enthalpy. A fine hybrid type numerical grid with 332,584 elements was used, where to accurately determine the boundary layer characteristics (shear stresses and heat fluxes) of iced surface, a $y+$ value less than 1 was used near the louver's surface. Shear stress and heat fluxes are quite important for the calculation of the rate of 
atmospheric ice accretion at the surface. Figure-2 shows the hybrid numerical grid used for this numerical study.

The sand grain roughness height for the iced surface was calculated with an empirical NASA correlation described by Shin et al. $[11,12]$. The corresponding value of the sand grain roughness is obtained from the correlation in equation (4):
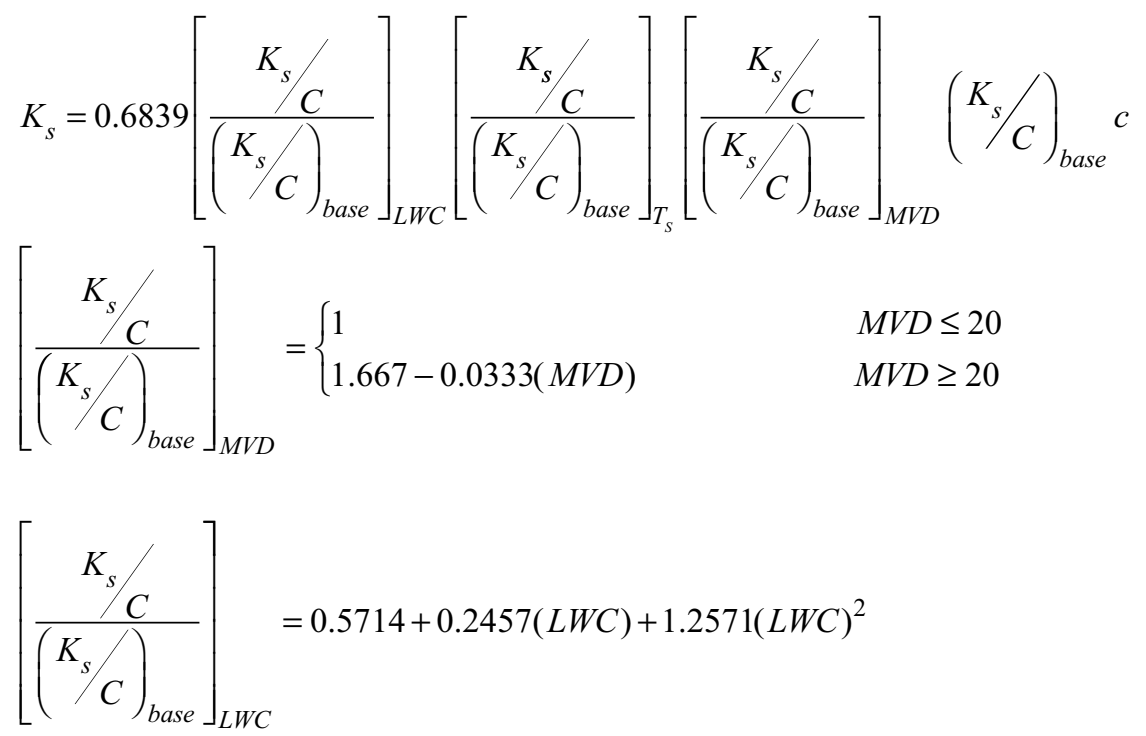

$$
\left[\frac{K_{s} / C}{\left(K_{s} / C\right)_{\text {base }}}\right]_{T_{S}}=0.04 T_{S}-11.27
$$

Where $M V D$ is the droplet mean diameter, the constant parameter $\left(K_{s} / C\right)_{\text {base }}=0.001177$. Two phase flow (air \& water droplets) was solved using the Eulerian-Eulerian approach, where super cooled water droplets were assumed to be spherical. The main advantage of using the Eulerian-Eulerian approach is that: the same mesh can be used for multiphase flow calculations and ice geometry. The Eulerian two phase fluid model consists of the NavierStokes equation, augmented by water droplets continuity and the momentum equation. The water droplet drag coefficient is based on the empirical correlation for the flow around the spherical droplets described by Clift et al. [13].

$$
\begin{aligned}
& \frac{\partial \alpha}{\partial t}+\vec{\nabla} \cdot\left(\alpha \vec{V}_{d}\right)=0 \\
& \frac{\partial\left(\alpha \vec{V}_{d}\right)}{\partial t}+\vec{\nabla} \cdot\left(\alpha \vec{V}_{d} \cdot \vec{V}_{d}\right)=\frac{C_{D} \operatorname{Re}_{d}}{24 k} \alpha\left(\vec{V}_{a}-\vec{V}_{d}\right)+\alpha\left(1-\frac{\rho_{a}}{\rho_{d}}\right) \frac{1}{F r^{2}} \vec{g}
\end{aligned}
$$



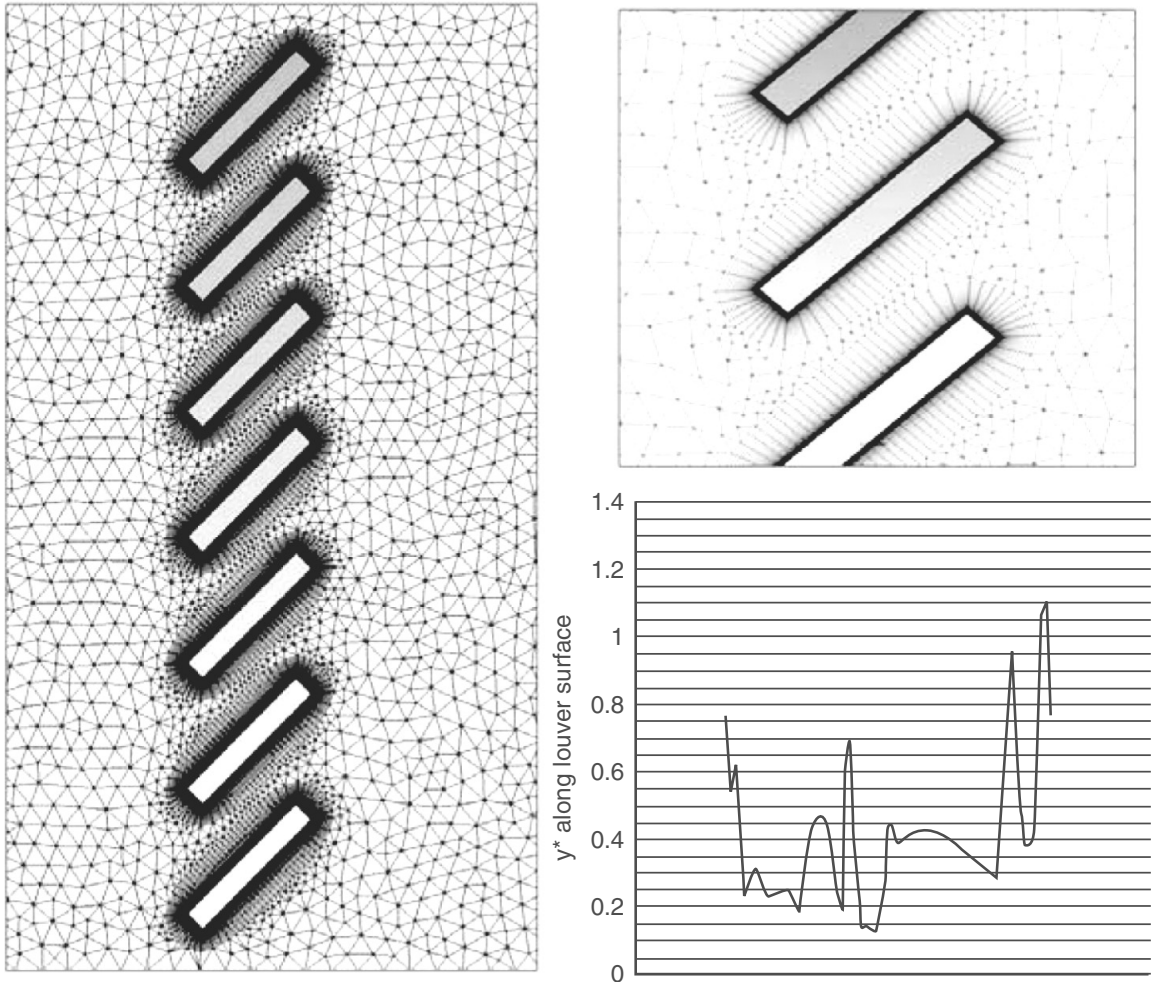

Figure 2 Hybrid numerical grid and $y+$ values near the wall used for simulation.

Where $\alpha$ is the water volume fraction, $V_{d}$ is the droplet velocity, $C_{D}$ is the droplet drag coefficient and $\mathrm{Fr}$ is the Froude number. Surface thermodynamics and rate of icing are calculated using mass and energy conservation equations, considering the heat fluxes due to convective cooling, evaporative cooling, heat of fusion, viscous heating, kinetic heating and solar radiation [14]:

$Q_{\text {in }}^{o}=Q_{\text {out }}^{o}$

$Q_{\text {latent heat }}+Q_{\text {aerodynamic heat }}+Q_{K E \text { heat }}$

$=Q_{\text {sublimative heat }}+Q_{\text {convective heat }}+Q_{\text {droplet, cooling heat }}+Q_{\text {radiative heat }}$

$Q_{\text {aerodynamic, heating }}=\frac{r h_{c} v_{\alpha}^{2}}{2 C_{p}}$

$Q_{\text {latent, heat }}=\left(L W C \cdot \beta \cdot v_{\alpha}\right) \cdot\left[L_{f}+C_{i}\left(T_{\text {air }}-T_{\text {surface }}\right)\right]$

$Q_{\text {droplrt, kinetic, energy }}=\left(L W C \cdot \beta \cdot v_{\alpha}\right) \frac{v_{\alpha}^{2}}{2}$ 


$$
\begin{aligned}
& Q_{\text {convection }}=h_{c}\left(T_{\text {surface }}-T_{\text {air }}\right) \\
& Q_{\text {sublimation }}=\chi_{s} e_{o}\left(T_{\text {surface }}-T_{\text {air }}\right) \\
& \chi_{s}=\frac{0.622 h_{c} L_{s}}{C_{p} P_{t} L_{e}^{0.66}} \\
& Q_{\text {droplet, cooling }}=\rho_{a} \beta v_{\alpha} C_{p, w}\left(T_{\text {surface }}-T_{\text {air }}\right) \\
& Q_{\text {radiation }}=4 \varepsilon \sigma_{r} T_{\text {air }}^{3}\left(T_{\text {surface }}-T_{\text {air }}\right)
\end{aligned}
$$

Where $r$ is the adiabatic recovery factor, $h_{c}$ is the convective heat transfer coefficient, $c_{i}$ is the specific heat of ice, $L_{f}$ is the latent heat of fusion, $L_{s}$ is the latent heat of sublimation, $L_{e}$ is the Lewis number and $\varepsilon$ is the surface emissivity. Arbitrary Langrangian Eulerian (ALE) formulation was used for the calculation of mesh displacement due to ice accretion in time. This approach adds the grid speed terms to the Navier-Stokes equations to account for mesh velocity [12]. The numerical simulations were carried out at the operating and geometric conditions specified in Table-1.

\section{RESULTS \& DISCUSSION}

\subsection{ICE ACCRETION ON AIR INTAKE LOUVER}

Initial numerical analyses were carried out to understand the airflow and water droplet behaviour around the louvers and to simulate the resultant ice accretion. CFD based finite element numerical anlayses of airflow through louver slats show the classical venturi effect in the vena contracta of each louver slat. As air moves from larger corss section to smaller corss section of the louver slat, the corrosponding higher air volume moves at a greater speed through the cross section. Thus, as the air speed between louver slats increases, the dynamics pressure in the region increases with a drop in the static pressure. A flow seperation occurs at the sharp corner edges of the louver slats causing local changes in air velocity. Air and supercooled water droplets are coupled with each other, therefore airflow behaviour affects the movement of the droplets along the surface. A droplet moving in the air stream is generally influenced by its drag and inertia, when neglecting the gravity and buoyancy. If drag dominates the inertia the droplet follows the stream line, whereas for the case where inertia dominates the particle hits the object. The ratio of inertia to drag depends upon droplet size, air velocity and dimensions of the object in question $[15,16]$. Analyses showed high droplet collison with the upper and front surfaces of the louvers, which leads to an increase in ice accretion along the upper and front surfaces of the louver slat. Such high droplet collision at the front and top surfaces of the louvers is mainly

Table 1 operating conditions used for the simulations.

\begin{tabular}{lr} 
Free Stream Wind Velocity $[\mathrm{m} / \mathrm{s}]$ & 10 \\
\hline Droplet Size , $M V D[\mu \mathrm{m}]$ & 40 \\
\hline Liquid Water Content,$L W C\left[\mathrm{~g} / \mathrm{m}^{3}\right]$ & 1.2 \\
\hline Atmospheric Air Temperatures $\left[{ }^{\circ} \mathrm{C}\right]$ & -10 \\
\hline Simulation Time [minutes] & 15 \\
\hline
\end{tabular}




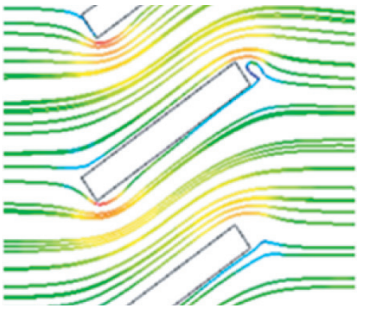

(Air velocity streamline)

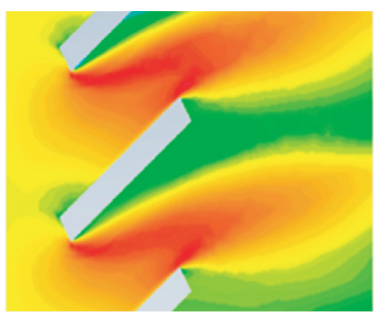

(Droplet velocity)

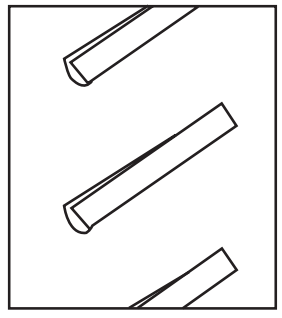

(Ice accretion)

Figure 3 Flow behavior and resultant ice accretion on louvers slat.

due to higher exposure of these sections to the stream of air and water droplets. Figure-3 shows air and droplet behaviours along the slat surface and the resultant shape of the accreted ice.

\subsection{GEOMETRIC PARAMTERIC ANALYSES}

Initial numerical results showed that ice accrets at the front and top ends of the louver slats. The rate and shape of ice accretion on structures can be minimised by optimizing the geomatric parameters. This section describes a geometric parameter study to analyse the effects of the louver slat's angle, shape and displacement on the resultant rate and shape of ice accretion. For this purpose; an air intake louver frame with seven slats was numerically modelled, where air and droplet behaviour around each louver slat was analysed to simulate the rate and shape of ice accretion.

\subsubsection{Effect of louver slat placement angle}

To study the effect of louver slat placement angle on flow behaviour and the resultant ice accretion, three different louver slats angles $(25,35 \& 45$ degree) were numerically analysed, where the distance between each slat in the louvered structure was $57 \mathrm{~mm}$. Results showed a change in the air and droplet behaviour with the change in louvers placement angle. At a low slat angle of 25 degrees, a more stramlined flow was observed as compared to high angled slats of 45 degrees. This leads to more attached flow and less flow seperation along the slat surface at low placement angles, which causes a low pressure drop between the inlet and outlet of the louver slats. Figure- 4 shows the velocity steamlines along the louver slats at three different slat angles:

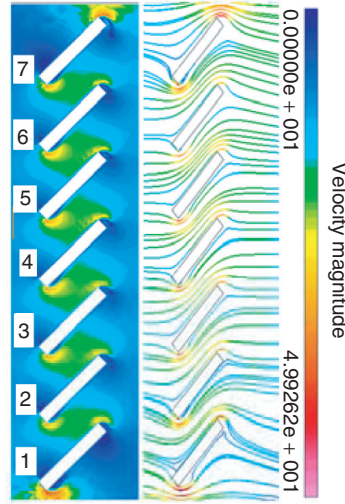

$45 \mathrm{deg}$

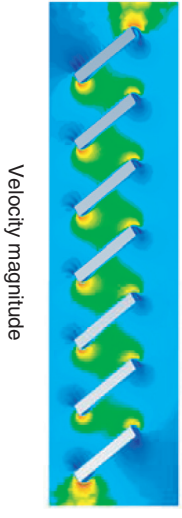

$35 \mathrm{deg}$

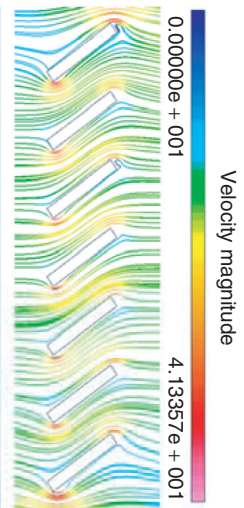

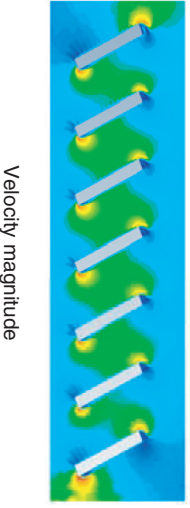

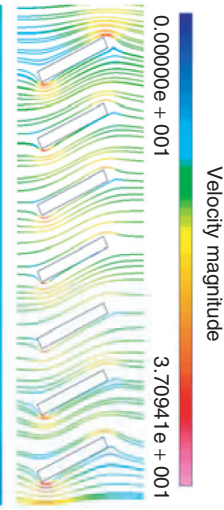

$25 \mathrm{deg}$

Figure 4 Effect of angle variation: air velocity streamlines and vector distribution. 
Study of the super cooled droplet behaviour with the change of slat angles shows a high droplet collison efficiency at low slat angles near the front end of the slat surface, whereas with the incraese of the slat angle, a larger area of the upper surface of the slat is exposed to the droplets which leads to higher droplet collison efficiency. This results in an increased ice accretion at the front end of the slat surface at low angles. On the other hand, more ice accretion is observed at the top surface of the slat in the case of high slat angles. Figures 5-7 show the droplet collision efficincy along the slat surface at different angles and the resultant ice thickness and growth along the slat surface.
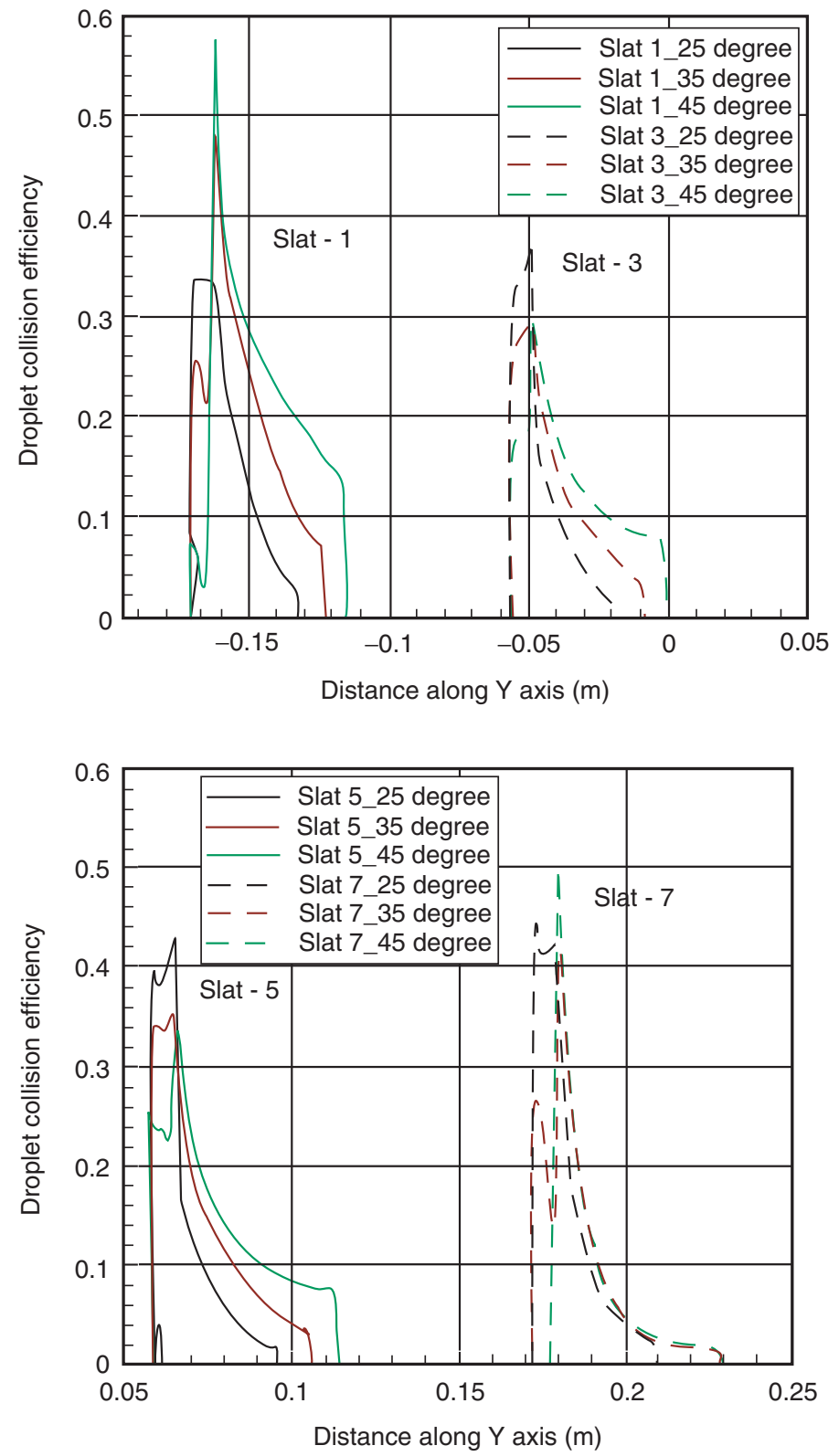

Figure 5 Effect of slat angle variation on the droplet collision efficiency. 

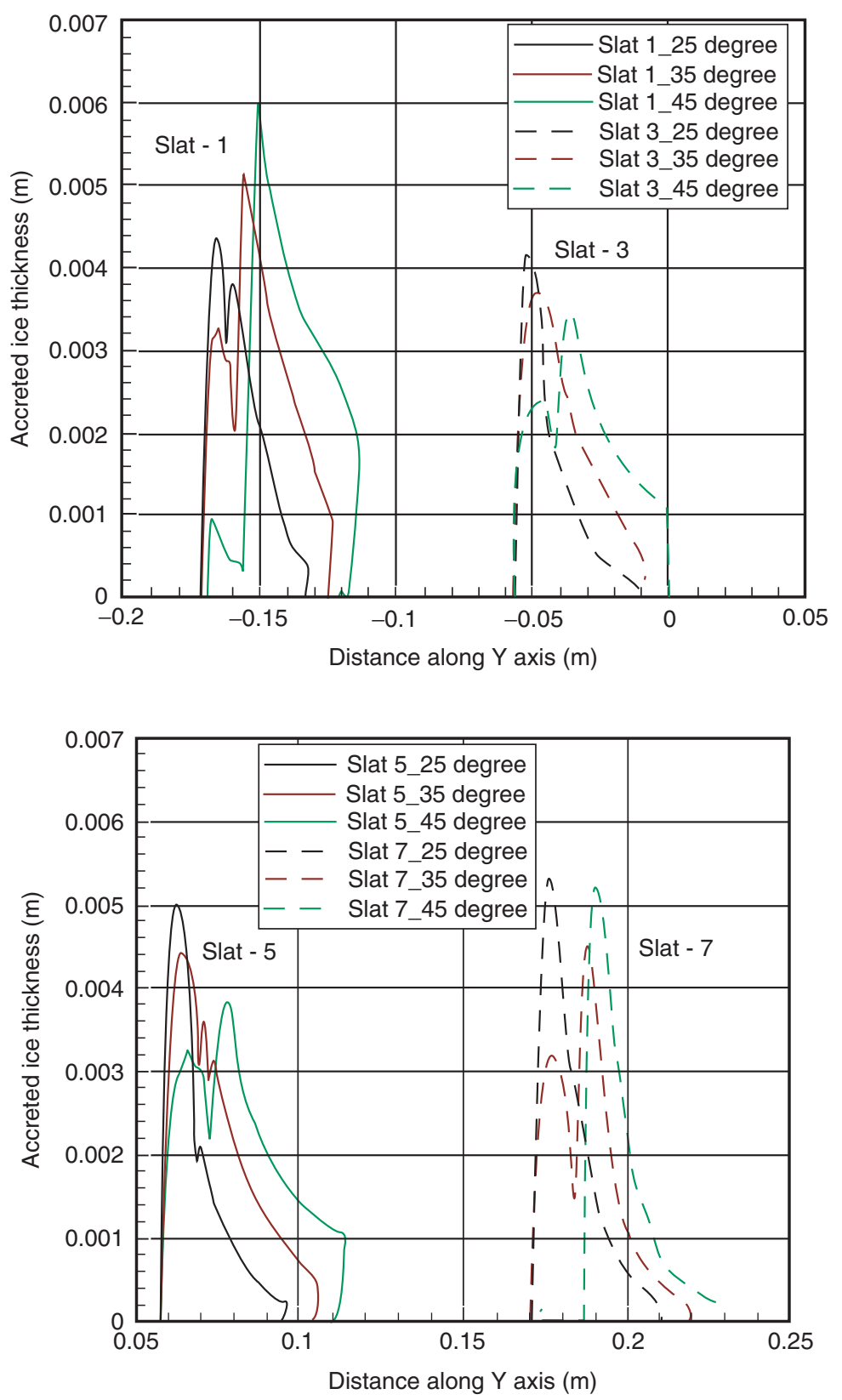

Figure 6 Effect of slat angle variation on accreted ice thickness.

\subsubsection{Effect of louver slat spacing variation}

To study the effect of louver slat spacing on the resultant ice accretion, three different slat spacings $(40,57 \& 75 \mathrm{~mm})$ were numerically analysed at a louver slat angle of 35 degrees. Analyses showed a high droplet collison efficiency at the front end of the louver slats in the case of $75 \mathrm{~mm}$ spacing, whereas in the case of $40 \mathrm{~mm}$ slat spacing, a high value of droplet collision is observed at the top surface of the louver slats. As an over all, the results showed 

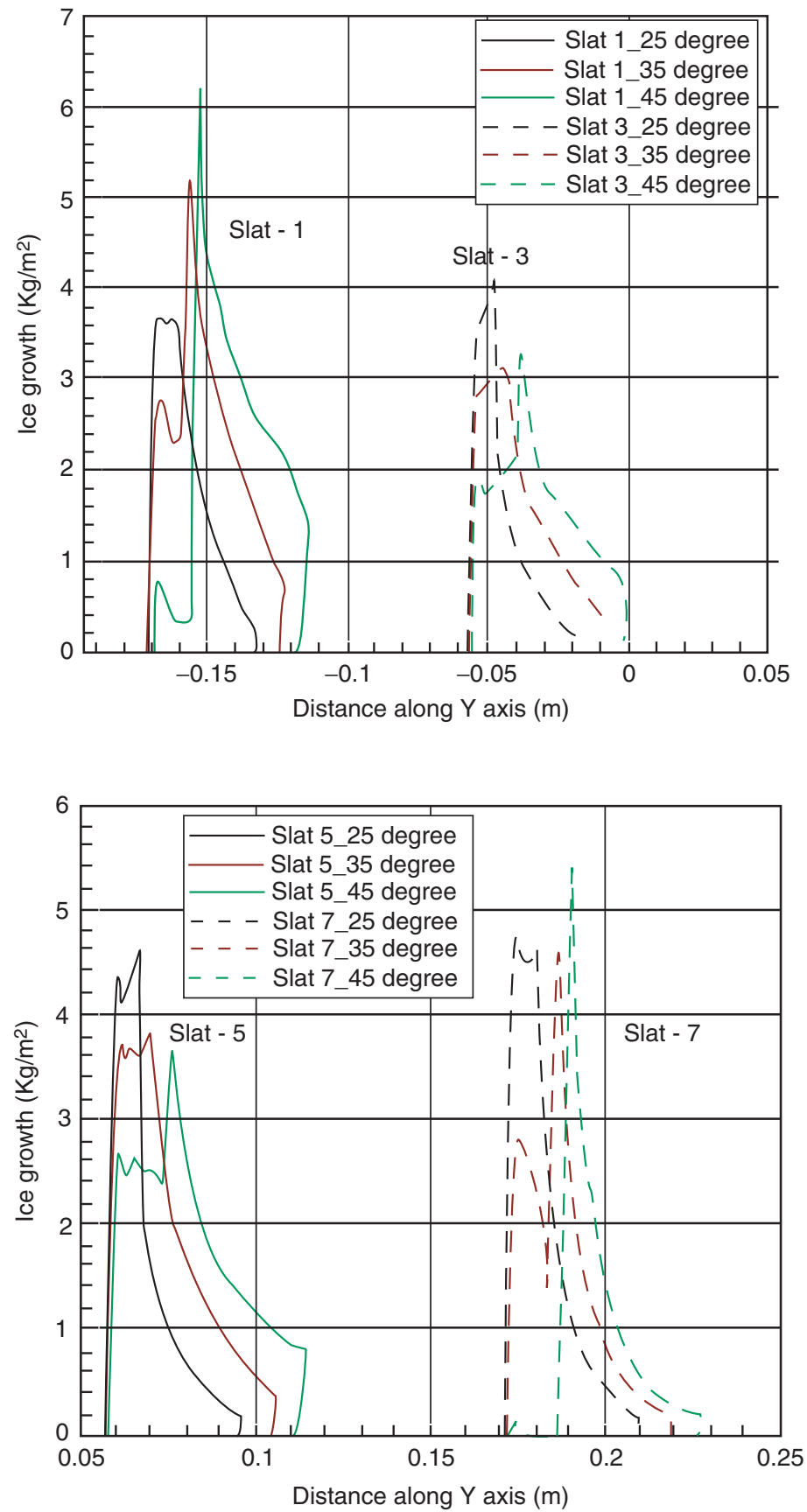

Figure 7 Effect of slat angle variation on accreted ice growth.

a high droplet collision efficiency in the case of small slat spacing $(40 \mathrm{~mm})$, as compared to the $75 \mathrm{~mm}$ slat spacing. This leads to more ice accretion in the case of small spacing between the louver slats. Figure- 8 shows the droplet collision efficiency and the resultant ice accretion on louver slats considering three different slat spacings. 

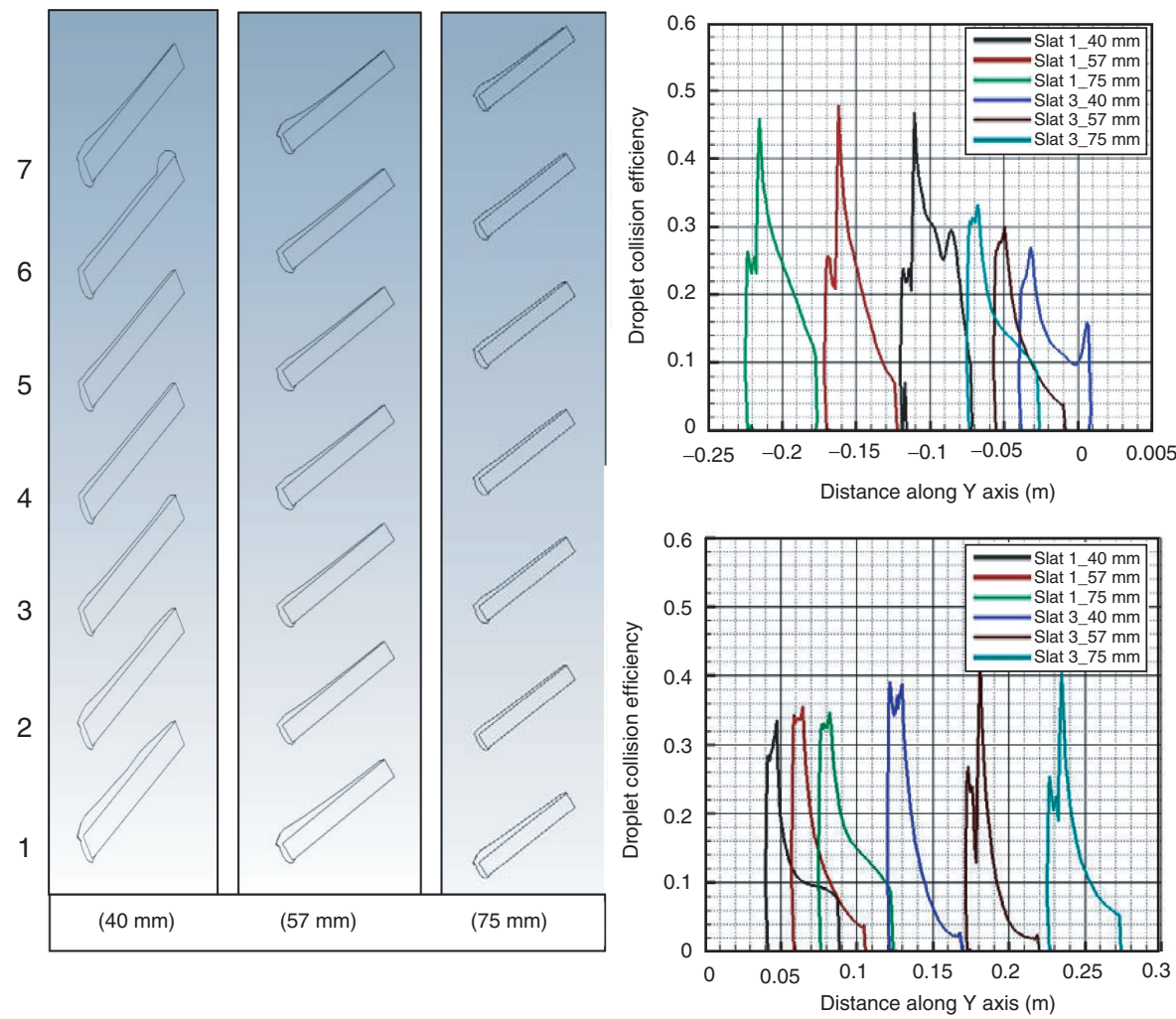

Figure 8 Effect of slat spacing variation on droplet collision and the resultant ice accretion.

\subsubsection{Effect of louver slat corners shape variation}

Louver slats corners can be of different shapes. This section describes the analyses for two different shapes of slats corners (rectangular \& circular), to reduce the flow seperation at sharp corners of the slat surfaces. Results showed streamlined behaviour for the circular shape as comapred to the rectangular shape corners, which results in smooth ice accretions at the corners of the slats. Smooth droplet distribution leads to smooth accreted ice shapes at the corners in the case of circular shapes, whereas an abrupt ice shape was observed in the case of rectanular corners. Figure- 9 shows the droplet collision efficiency and the resultant ice growth on louver slats in the case of rectangular and circular corners.

\section{FINDINGS}

This present numerical study has provided a basic understanding of the airflow and water droplet behaviour around buildings air intake louver slats and the resultant ice accretion at various geometric conditions. Following are the main findings of this study.

- Ice accretion occurrs mainly at the front and top surfaces of the air intake louver slats.

- More ice accretion is found at the front end of the louver slats at small placement angles, whereas more ice accretes at the top surface of the louvers slats at higher placement angles. As an over all assessment, an increase in the ice accretion is observed with the increase in slats angle. 

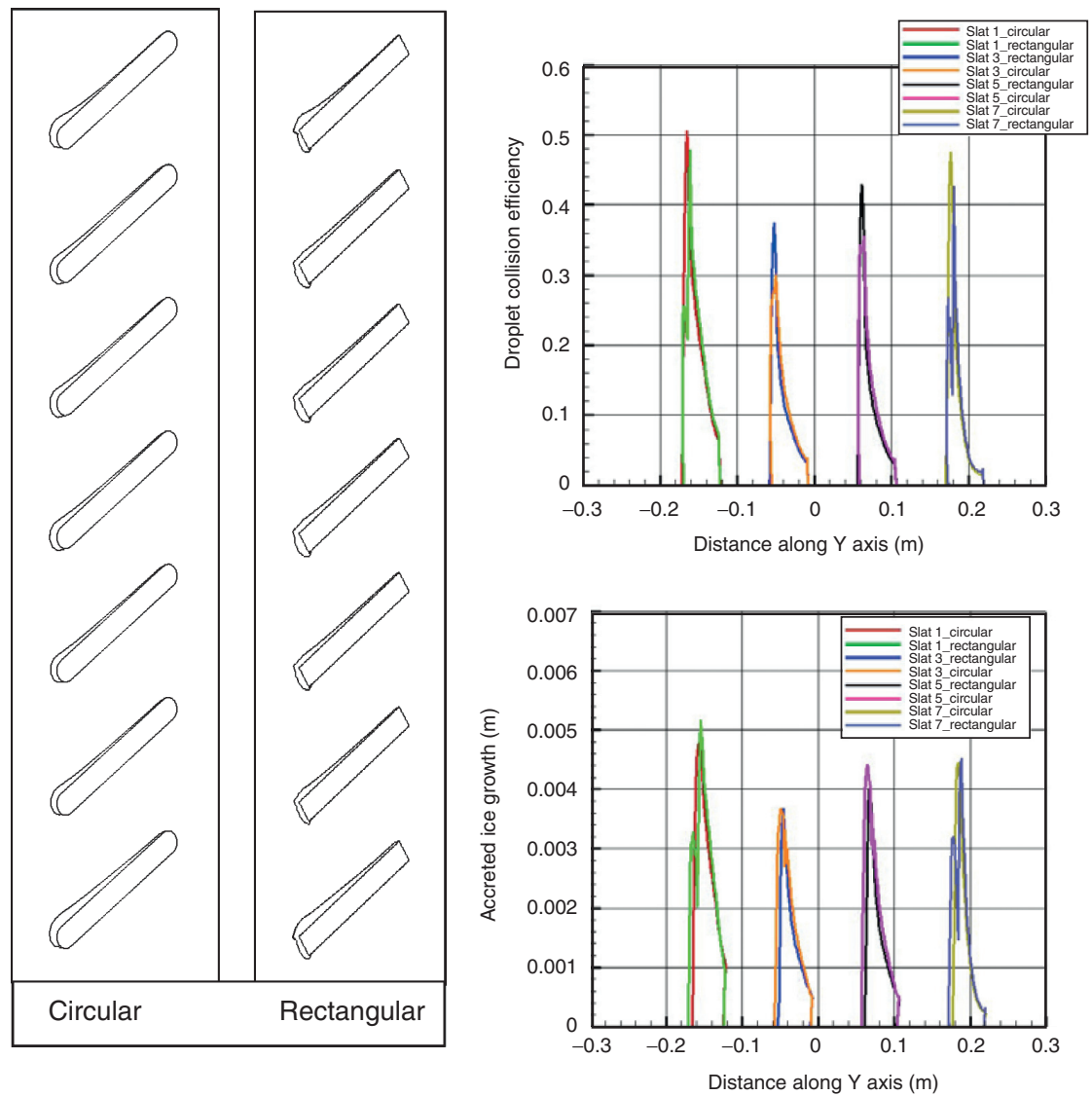

Figure 9 Effect of slats corner shape variation on droplet collision and ice accretion.

- More ice accretion occurrs at the front end of the louver slats with the increase in spacing between louver slats, whereas more ice accretes at the top surface of the louver slat with the decrease in slat spacing. As an over all observation, an increase in the ice accretion is observed with the decrease in spacing between slats.

- A more streamlined flow behaviour is observed in the case of circular shape slat corners as comapred to rectangule shape, this leads to a smoother accreted ice shape in the case of circular slat corner.

\section{ACKNOWLEDGMENT}

The work reported in this paper was partially funded by the Research Council of Norway, project no. 195153/160 and partially by the consortium of the ColdTech project - Sustainable Cold Climate Technology.

\section{REFERENCES}

[1] Toshikazu Nakanishi, et al., Investigation of Air Flow passing through Louvers in Komatsu Technical Report 2007.

[2] Chandrashekaran, D., AIR FLOW THROUGH LOUVERED OPENINGS: EFFECT OF LOUVER SLATS ON AIR MOVEMENT INSIDE A SPACE, in FACULTY OF THE USC 
SCHOOL OF ARCHITECTURE2010, UNIVERSITY OF SOUTHERN CALIFORNIA: CALIFORNIA. p. 140.

[3] G M Stavrakakisa, et al., Natural cross-ventilation term in buildings: Building-scale experiments, numerical simulation and thermal comfort evaluation. Energy \& Buildings, 2008. 40(9): p. $1666-1681$.

[4] Steve Sharples and C. Nelson, Performance of ventilator components for natural ventilation applications. Buildings and Environment, 2006. 41(12): p. 1821-1830.

[5] G S Yakubu and S. Sharples., Airflow through modulated louvre systems. Building Services Engineering Research and Technology, 1991. 12: p. 151-155.

[6] Steve Sharples and A. Maghrabi. Airflow through louvers : An experimental and CFD study. in 21 st Annual AIVC Conference: Innovations in ventilation technology. 2000. Hauge.

[7] Tablada, et al. Exterior Louvers as a Passive Cooling Strategy in a Residential Building: Computational Fluid Dynamics and building energy simulation modelling. in PLEA 2009 - 26th Conference on Passive and Low Energy Architecture. 2009. Quebec.

[8] Hughes, Ben Richard, and A. Ghani., numerical investigation into the effect of Windvent louvre external angle on passive stack ventilation performance. Building and Environment, 2010. 45(4): p. $1025-1036$.

[9] Ping Fu, Masoud Farzaneh, and G. Bouchard, Two dimensional modelling of the ice accretion process on transmission line wires and conductors. Cold region science \& technology, 2006. 46: p. 132-146.

[10] T Wagner, U PEil, and C. Borri., Numerical investigation of conductor bundle icing, in EACWE 52009: Florence, Italy.

[11] J Shin and T.H. Bind., Experimental and computational ice shapes and resulting drag increase for a NACA 0012 airfoil, 1992, NASA technical memorandum 105743.

[12] Manual, N.S.U., 2010, NTI.

[13] R Clift, J R Grace, and M.E. Weber, Bubbles, Drops and Particles. 1978, New York: Academic Press.

[14] S O" zgen and Æ.M. Canıbek, Ice accretion simulation on multi-element airfoils using extended Messinger model. Heat Mass Transfer, 2009. 45: p. 305-322.

[15] Muhammad S Virk, Matthew C Homola, and P.J. Nicklasson., Effect of rime ice accretion on aerodynamic characteristics of wind turbine blade profiles. Wind Engineering 2010. 34(2): p. 207-218.

[16] Muhammad S Virk, et al., Efect of atmospheric temperature and droplet size variation on ice accretion of wind turbine blades,. Journal of wind engineering and industrial aerodynamics, 2010. 98: p. $724-729$ 